\title{
The atmospheric background situation in northern Scandinavia during January/February 2003 in the context of the MaCWAVE campaign
}

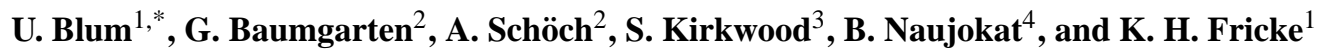 \\ ${ }^{1}$ Physikalisches Institut der Universität Bonn, 53115 Bonn, Germany \\ ${ }^{2}$ Leibniz-Institut für Atmosphärenphysik e.V., 18225 Kühlungsborn, Germany \\ ${ }^{3}$ Institutet för rymdfysik, 98128 Kiruna, Sweden \\ ${ }^{4}$ Meteorologisches Institut der Freien Universität Berlin, 12165 Berlin, Germany \\ *now at: Forsvarets forskningsinstitutt, 2027 Kjeller, Norway
}

Received: 11 April 2005 - Revised: 6 September 2005 - Accepted: 16 September 2005 - Published: 3 July 2006

Part of Special Issue "MaCWAVE: a rocket-lidar-radar program to study the polar mesosphere during summer and winter"

\begin{abstract}
The atmosphere background wind field controls the propagation of gravity waves from the troposphere through the stratosphere into the mesosphere. During January 2003 the MaCWAVE campaign took place at Esrange, with the purpose of observing vertically ascending waves induced by orography. Temperature data from the U. Bonn lidar at Esrange $\left(68^{\circ} \mathrm{N} / 21^{\circ} \mathrm{E}\right)$ and the ALOMAR RMR lidar $\left(69^{\circ} \mathrm{N} / 16^{\circ} \mathrm{E}\right)$, wind data from Esrange MST radar ESRAD, as well as wind data from the ECMWF T106 model, are used to analyse the atmospheric background situation and its effect on mountain wave propagation during January/February 2003. Critical levels lead to dissipation of vertically ascending waves, thus mountain waves are not observable above those levels. In the first half of January a minor as well as a major stratospheric warming dominated the meteorological background situation. These warmings led to a wind reversal, thus to critical level filtering and consequently prevented gravity waves from propagating to high altitudes. While the troposphere was not transparent for stationary gravity waves most of the time, there was a period of eight days following the major warming with a transparent stratosphere, with conditions allowing gravity waves generated in the lower troposphere to penetrate the stratosphere up to the stratopause and sometimes even into the lower mesosphere. In the middle of February a minor stratospheric warming occurred, which again led to critical levels such that gravity waves were not able to ascend above the middle stratosphere. Due to the unfavourable troposphere and lower stratosphere conditions for gravity wave excitation and propagation, the source of
\end{abstract}

Correspondence to: U. Blum

(ubl@ffi.no) the observed waves in the middle atmosphere is probably different from orography.

Keywords. Atmospheric composition and structure (Pressure, density, and temperature) - Meteorology and atmospheric dynamics (Middle atmosphere dynamics; Waves and tides)

\section{Introduction}

The Scandinavian mountain ridge is a major source for the excitation of gravity waves in the Arctic polar atmosphere (e.g. Volkert and Intes, 1992; Schöch et al., 2004). Given an appropriate wind profile these orographic gravity waves will propagate well into the middle atmosphere (Scorer, 1949). Wind shears create critical levels in the atmosphere, which lead to dissipation of vertically ascending gravity waves (e.g. Fritts, 1984; Fritts and Alexander, 2003, and references therein). Thus, mountain waves are not observable above such critical levels. Stratospheric warmings or stratospheric temperature enhancements occur frequently in the polar winter atmosphere (Labitzke and Naujokat, 2000; Meriwether and Gerrad, 2004, and references therein) and modify the mean zonal wind. Major stratospheric warmings lead to the breakdown of the polar vortex and to a wind reversal in the stratosphere (Matsuno, 1971).

The U. Bonn lidar at Esrange $\left(68^{\circ} \mathrm{N} / 21^{\circ} \mathrm{E}\right)$, located near the city of Kiruna in northern Sweden (Blum and Fricke, 2005), and the ALOMAR RMR lidar $\left(69^{\circ} \mathrm{N} / 16^{\circ} \mathrm{E}\right)$ located on the Norwegian island of Andøya (von Zahn et al., 2000), were operated during January and February 2003 on both sides of the Scandinavian mountains. Both lidar stations are

Published by Copernicus GmbH on behalf of the European Geosciences Union. 


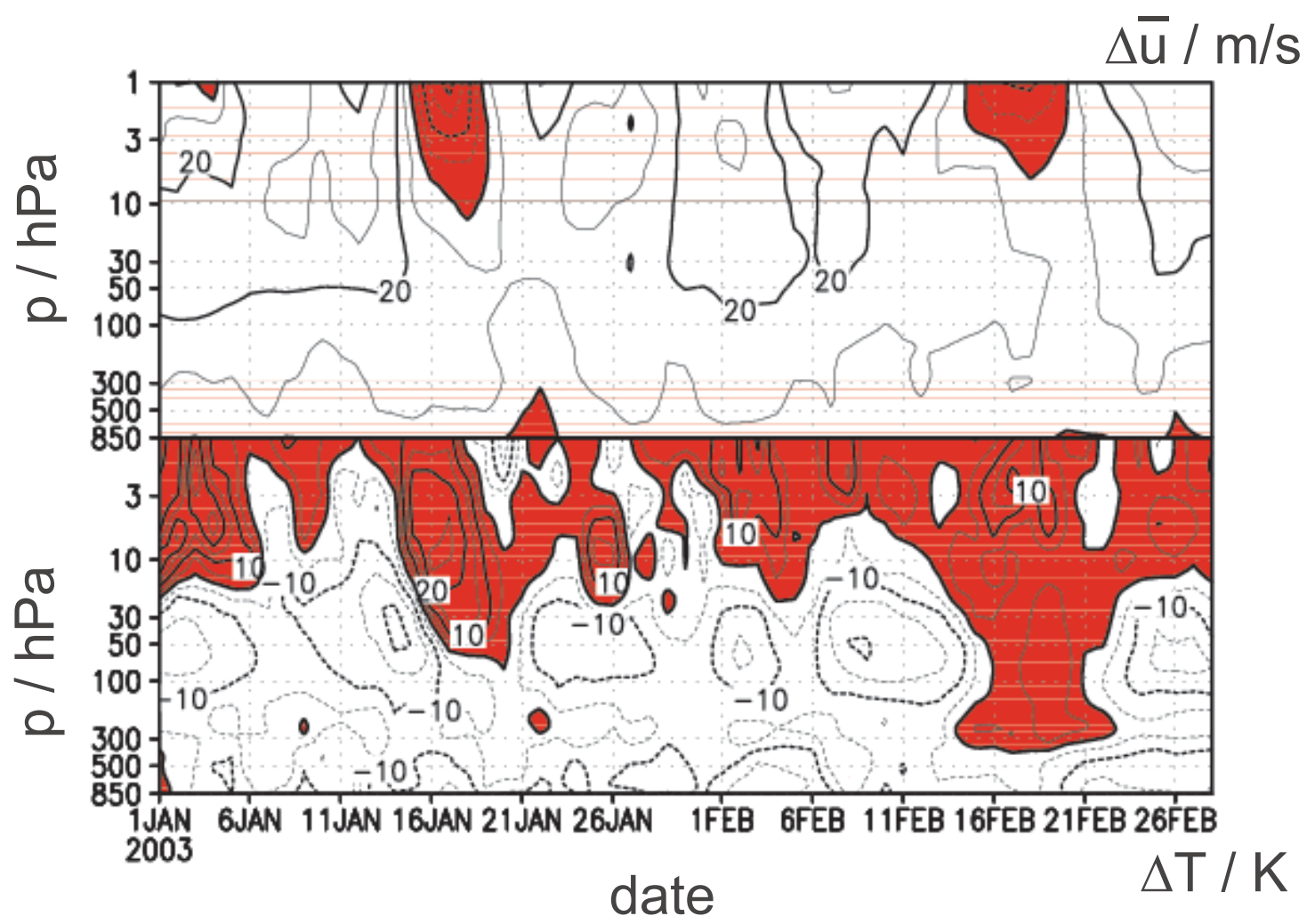

Fig. 1. Time-height section of zonal mean zonal wind in $\mathrm{m} / \mathrm{s}$ (upper plot) at $60^{\circ} \mathrm{N}$ and of temperature gradient in $\mathrm{K}$ (lower plot) between $60^{\circ} \mathrm{N}$ and the North Pole from 1 January to 28 February 2003 (ECMWF data); westward winds and positive temperature gradients are red. The ordinate is atmospheric pressure in $\mathrm{hPa}$.

able to derive temperature profiles from the middle stratosphere to the mesosphere, assuming hydrostatic equilibrium and integrating the range corrected lidar net signal (Kent and Wright, 1970; Hauchecorne and Chanin, 1980). These measurements cover almost continuously the time period from 2 January to 19 February 2003 and thus give an exhaustive overview of the atmospheric temperature development above northern Scandinavia near the Arctic circle. In addition, tropospheric wind data can be determined with a high vertical and temporal resolution from the measurements of the ESRAD MST radar which is also located at Esrange (Chilson et al., 1999). Further, the ECMWF T106 analyses give temperature and wind data from the ground to $0.1 \mathrm{hPa}$, which is at about $60 \mathrm{~km}$ altitude, at 28 altitude levels. These analyses allow a hemispheric perspective. The combination of temperature and wind data leads to an understanding of the hemispheric meteorological background situation, and the combination of model and experimental data focuses on the implications of this hemispheric situation on mountain wave propagation above northern Scandinavia.

The winter part of the MaCWAVE (Mountain and Convective Waves Ascending Vertically) rocket and balloon campaign, which took place during the second half of January, aimed at the detection of mountain waves which ascend vertically into the mesosphere (e.g. Goldberg et al., 2005). Using the lidar, radar, and ECMWF data we will assess the possibilities for orographically induced gravity waves to penetrate from the lower troposphere throughout the stratosphere up to the mesosphere during January and February 2003, in particular regarding the MaCWAVE salvos on 24 and 28 January 2003.

Parallel to the MaCWAVE campaign one phase of the Validation of International Satellites and Study of Ozone Loss (VINTERSOL) project took place in Northern Scandinavia. While the MaCWAVE campaign focussed on gravity waves travelling to the mesosphere, the purpose of the VINTERSOL campaign was to observe stratospheric ozone and other trace gases as well as polar stratospheric clouds (PSC). As PSC form regularly in temperature minima caused by atmospheric gravity waves (e.g. Carslaw et al., 1998; Dörnbrack and Leutbecher, 2001; Blum et al., 2005, and references therein), the atmospheric dynamics are also of interest for this research.

\section{Hemispheric perspective}

We use ECMWF T106 data to detect and characterise stratospheric warmings on a hemispheric perspective. According to the stratalert criteria of the Free University Berlin (http: 


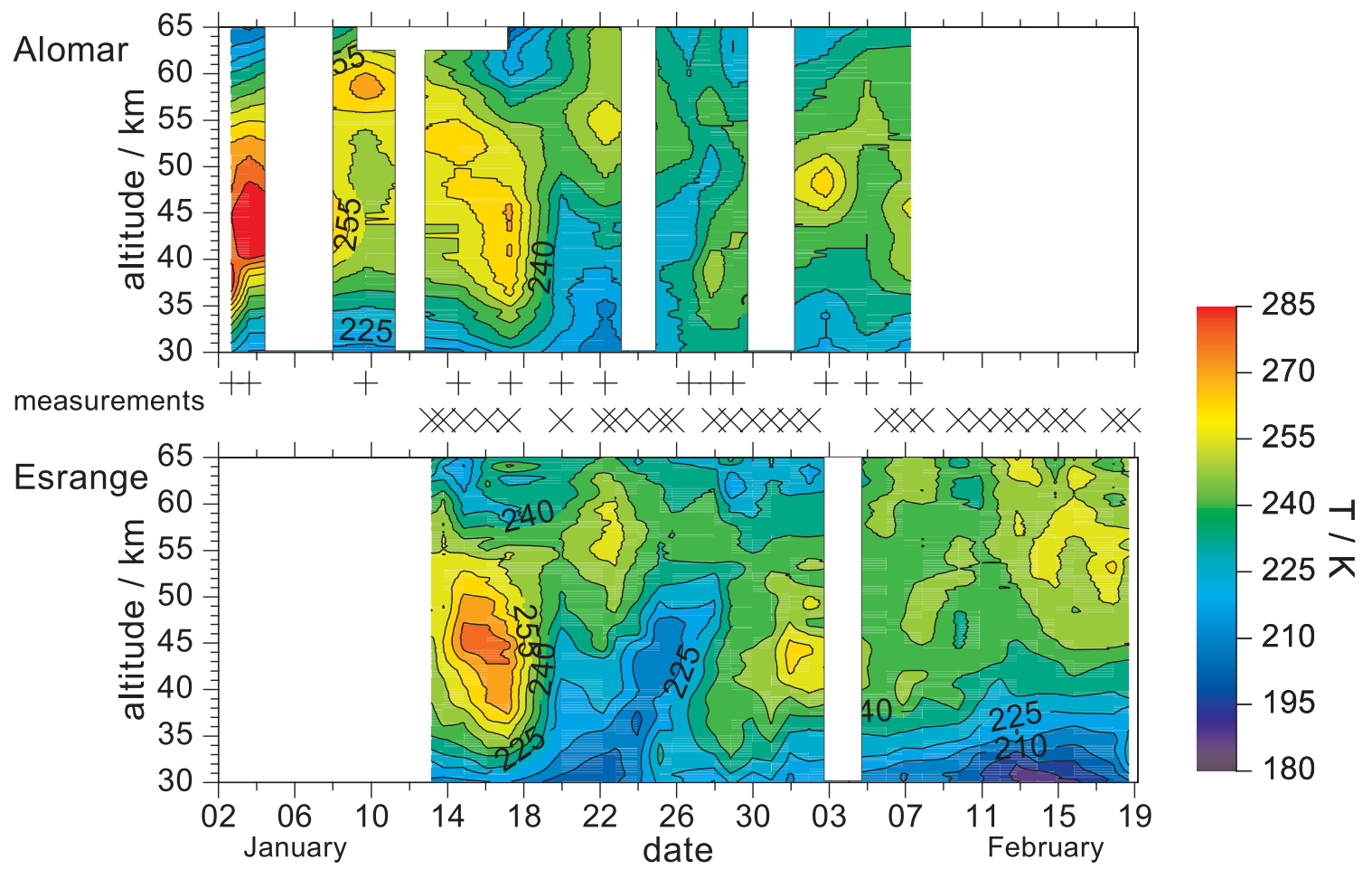

Fig. 2. Temperature development observed with the ALOMAR RMR lidar in Norway (upper panel) and the U. Bonn lidar at Esrange in Sweden (lower panel) for January/February 2003. On the abscissa is the date of January/February 2003, on the ordinate the altitude in km and colour coded the temperature in K. Measurement times are marked by plus-signs $(+)$ for ALOMAR data and by crosses $(\times)$ for Esrange data.

//strat-www.met.fu-berlin.de/products/alert.html), a minor stratospheric warming is defined by a temperature increase of at least $25 \mathrm{~K}$ in a period of a week or less at any stratospheric level in any area. If in the $10-\mathrm{hPa}$ level or below a reversal of the temperature gradient between $60^{\circ} \mathrm{N}$ and the North Pole and an associated circulation reversal is observed, then this warming is called a major warming.

Figure 1 shows the zonal mean zonal wind at $60^{\circ} \mathrm{N}$ (upper plot), as well as the temperature gradient between $60^{\circ} \mathrm{N}$ and the pole at the $10 \mathrm{hPa}$ level (lower plot). The temperature plot shows a reversed temperature gradient between $60^{\circ} \mathrm{N}$ and the pole (red shaded) during almost all of January and February 2003, however, the wind reversal (red shaded) reached below the $30 \mathrm{hPa}$ pressure level for only a few days during mid-January. Thus, one major stratospheric warming took place during this observation period covering 17-19 January, whereas minor warmings occurred almost continuously. These observations correspond very well with the findings by, for example Spang et al. (2005) and Singleton et al. (2005) in the context of the VINTERSOL campaign.

\section{Local perspective}

The local perspective of this winter in northern Scandinavia can be partly described by the temperature data derived from the lidar measurements at Esrange and at ALOMAR, as well as by the tropospheric wind data taken from the measurements of the ESRAD MST radar located at Esrange.

\subsection{Temperature data}

The temperature profiles retrieved by both lidars give an overview of the mean atmospheric temperature structure above northern Scandinavia.

Figure 2 shows the temperature development observed by the U. Bonn lidar at Esrange and the ALOMAR RMR lidar on Andøya. There were 13 measurement runs at ALOMAR, in the time period from 2 January to 7 February and 29 measurements at Esrange, beginning on 13 January and lasting to 18 February 2003. Thus, we have a good temperature coverage for nearly the entire time period of January/February 2003. These nightly mean temperature profiles show a similar structure on a coarse scale on both sides of the mountains but the details reveal differences. For a description of the atmospheric background situation, we concentrate on the similarities and not on the differences between both data sets. 


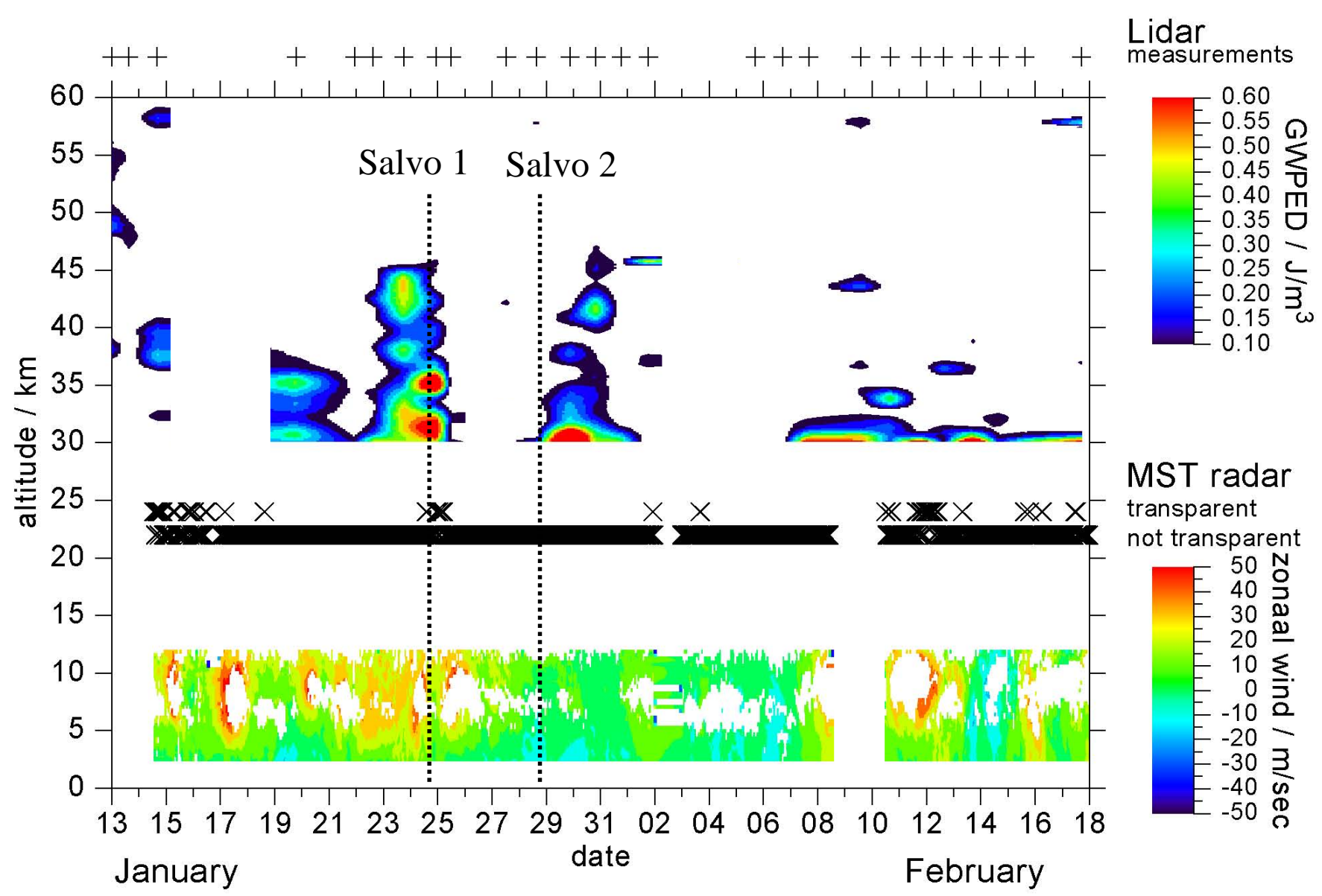

Fig. 3. Development of zonal wind as observed by Esrange MST radar ESRAD in the troposphere and the gravity wave potential energy density as observed by the U. Bonn lidar in the stratosphere. The abscissa gives the date of January/February 2003, the ordinate the altitude in $\mathrm{km}$ and the colour code in the lower part of the plot the zonal wind in $\mathrm{m} / \mathrm{s}$. The sign determines the direction of the zonal wind (+: eastward, -: westward). Crosses at about $25 \mathrm{~km}$ mark days when the excitation and propagation of orographically induced gravity waves was possible according to the wind data. The second colour bar in the upper part of the figure describes the $\mathrm{GWPED}_{\mathrm{vol}}$ in $\mathrm{J} / \mathrm{m}^{3}$. Crosses at the top of the figure mark the measurement times of the lidar.

A detailed study of the differences on both sides is given by Blum et al. (2004).

The first minor warming observed in the hemispheric view can also be found in the lidar temperature data. The ALOMAR lidar measures stratopause temperatures up to $309 \mathrm{~K}$ at an altitude of about $43 \mathrm{~km}$ during the first two measurement nights on 2 and 3 January. The following major warming was observed by both lidar stations. High stratopause temperatures of $270-280 \mathrm{~K}$ at about $45 \mathrm{~km}$ altitude are measured by both lidars during 15-17 January, where the stratopause temperature at Esrange was about $7 \mathrm{~K}$ warmer than above ALOMAR. At the end of the measurement campaign of the U. Bonn lidar on 18 February, again a warm stratopause with temperatures around $260 \mathrm{~K}$ was observed, which might be caused by the minor warming di- agnosed in the ECMWF data. This indicates that the hemispherically observed warming events took place above northern Scandinavia and thus were directly influencing the region.

Although the temperature profiles observed by the lidars cover only the lower mesosphere, these measurements indicate mesospheric coolings which are correlated with the stratospheric warmings. However, for a detailed analysis of this correlation, the quality of the available data set is not sufficient.

Following the second warming, unusually cold temperatures in the altitude range $30-50 \mathrm{~km}$ were observed during an eight-day period (19-27 January). Further in the beginning of February a six-day period (5-11 February) with almost isothermal temperature profiles from about $40-65 \mathrm{~km}$ 
altitude were observed, indicating the final recovery stage of the major warming observed at the beginning of January (Labitzke, 1972).

Although the hemispheric view does not assure a proper description of the local atmospheric conditions, the comparison of the hemispheric view with the local measurements of Esrange and ALOMAR lidars assures that the stratospheric warmings deduced from ECMWF analyses indeed affected the area above northern Scandinavia and thus influenced the excitation and propagation conditions for atmospheric gravity waves.

\subsection{Wind data}

The ESRAD MST radar measured nearly continuously during the winter 2002/2003. Horizontal wind data were determined by the spaced-antenna technique (Briggs, 1984) and the vertical velocity from the Doppler shift. The lower part of Fig. 3 shows the zonal wind for the time January/February 2003, where the sign determines the direction (+: eastward, - : westward).

Shown are hourly mean wind profiles with an altitude resolution of $300 \mathrm{~m}$ covering the altitude range from $2.4 \mathrm{~km}$ up to $14 \mathrm{~km}$. Sometimes the weak radar signal in the upper troposphere did not allow for the calculation of wind at the upper end of the altitude range.

Most of the time there were eastward winds during the winter in the troposphere, occasionally reaching more than $50 \mathrm{~m} / \mathrm{s}$. In particular, during the second half of January, the zonal wind exceeded $50 \mathrm{~m} / \mathrm{s}$ throughout a large part of the troposphere. Simultaneously with the stratospheric warming in the middle of January the wind decreased, as can be seen from the greenish colour in Fig. 3 on 16 January 2005 in the middle/upper troposphere.

\section{Wave excitation and propagation}

One important source for stationary gravity waves is orography. Based on numerical modelling, Dörnbrack and Leutbecher (2001) showed that several conditions must be met to allow orographically induced gravity waves to develop and to propagate through the troposphere into the stratosphere. For significant excitation of inertia mountain waves they require a minimal horizontal wind speed of $10 \mathrm{~m} / \mathrm{s}$ near the ground within an angle of $\pm 45^{\circ}$ perpendicular to the Scandinavian mountain ridge. Due to the fact that we do not concentrate only on mesoscale gravity waves but also on shorter-scale waves, originating on the local orography, we can ignore the direction of the horizontal wind and just focus on the horizontal wind speed, to test the probability of mountain wave excitation. The MST radar data show that the low-altitude winds during January/February 2003 were in $67 \%$ of all measurements below $10 \mathrm{~m} / \mathrm{s}$ and in $40 \%$ of all measurements even below $5 \mathrm{~m} / \mathrm{s}$. Obviously the chance for excitation of orographic gravity waves was low.

A simple criterion to check for the transparency of the troposphere for gravity wave propagation is given by the wind shear between the ground and the individual altitude level. A wind shear of more than $\pm 45^{\circ}$ leads to critical level filtering of mountain waves and can be verified by the wind data from the ESRAD MST radar. In the middle of Fig. 3 the measurements allowing for mountain wave excitation and propagation in the troposphere are marked according to the above-mentioned criteria and those leading to critical level filtering. From late January to mid February the transparency of the troposphere was poor.

Vertically ascending gravity waves can be detected in lidar temperature profiles. For analyses of the observed gravity waves we calculate, on the one hand, a night mean temperature profile, which includes all usable measurements of one night. On the other hand we split the lidar data for each night into segments, with a one-hour integration time, and compute for these shorter intervals different individual temperature profiles for one measurement night. Subtracting the night mean temperature profile from the individual profiles we obtain residual profiles which we attribute to variations induced by gravity waves. Time series of the residual profiles can be used to calculate the gravity wave potential energy density per volume $\left(G W P E D_{\mathrm{vol}}\right)$, which is defined as

$G W P E D_{\mathrm{vol}}(z)=\frac{1}{2} \frac{g^{2}(z)}{N^{2}(z)} \overline{\left(\frac{\Delta T(z)}{\overline{T(z)}}\right)^{2}} n(z) \bar{m}$.

This quantity consists essentially of the time mean of the squared relative temperature variance $\overline{(\Delta T(z) / \overline{T(z)})^{2}}$, where $\Delta T(z)$ is the temperature residual profile and $\overline{T(z)}$ is the night mean temperature profile. This temperature variation is further multiplied by a stability factor, $g^{2}(z) / N^{2}(z)$, where $g(z)$ is the acceleration due to gravity and $N$ is the Brunt-Väisälä frequency. The symbol $n(z)$ stands for the atmospheric number density taken from the lidar measurements, normalised to the ECMWF analyses, and $\bar{m}$ is the mean molecular mass. The GW PE $D_{\mathrm{vol}}$ is a measure for the energy available in the gravity waves and can be used to estimate energy dissipation with altitude; for dissipating waves it decreases with altitude. If it is constant with altitude, the energy is conserved in the ascending wave.

The upper part of Fig. 3 shows the calculated GW PE $D_{\text {vol }}$ development above Esrange. During the time period of the cold air event (19-27 January), there are several days with high reaching, large energy density values, whereas before and after that period the energy density of the waves dies out at about $35 \mathrm{~km}$ altitude or even below. Obviously, January and February 2003 were not favourable for mountain wave propagation through the troposphere and lower stratosphere to the upper stratosphere, for most of the time.

Vertically ascending gravity waves are characterised by a vertical wave number larger than zero. Using the simplified 


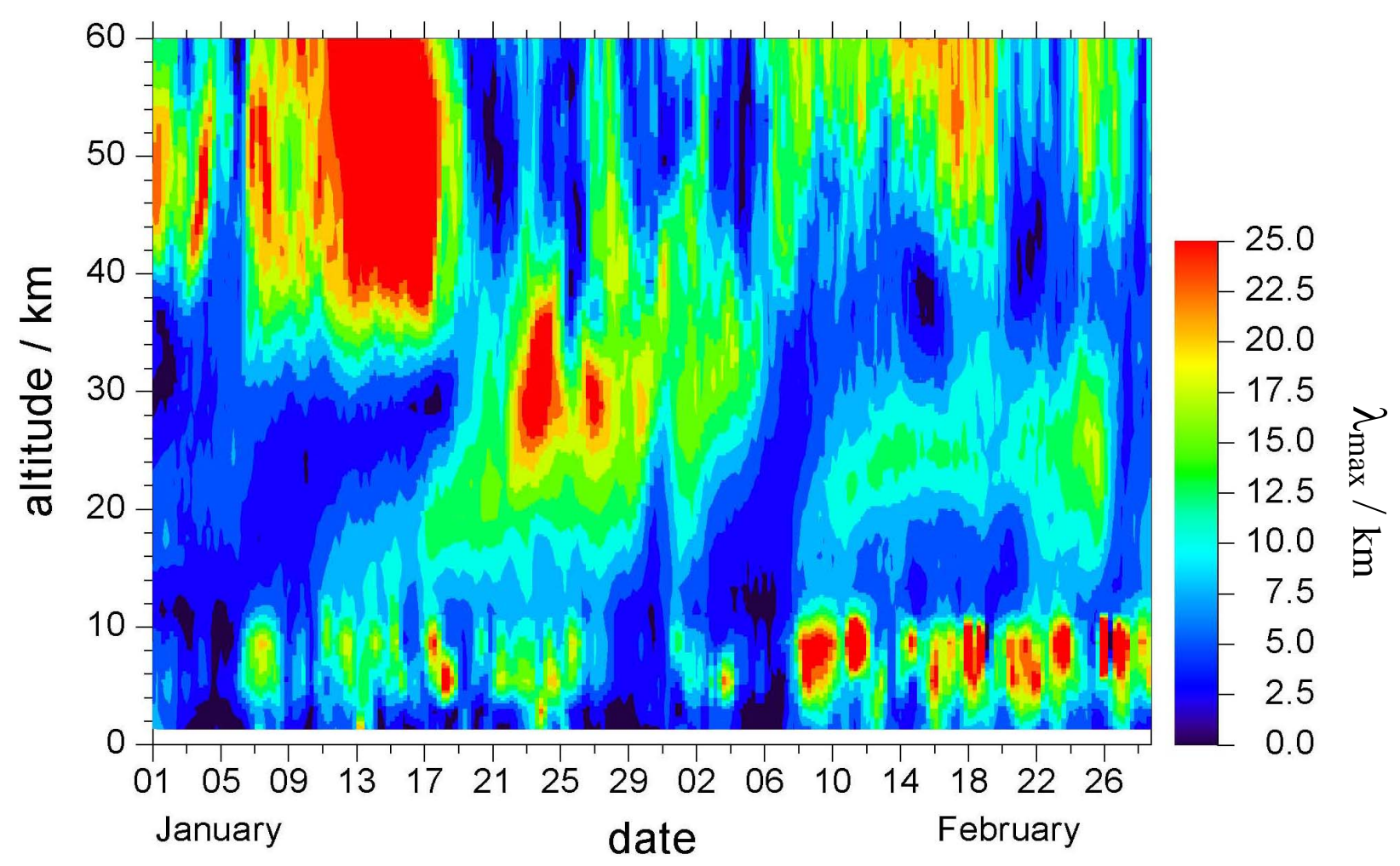

Fig. 4. Critical level calculation for Esrange with ECMWF T106 data. The abscissa shows the date of January/February 2003, the ordinate the altitude and the colour code the maximum vertical wavelength $\lambda_{\max }$, which can penetrate through the respective atmospheric levels. Dark blue areas are critical levels which inhibit vertical propagation of internal gravity waves.

Table 1. Key parameters for analysis of gravity wave acitivity.

\begin{tabular}{ll} 
Excitation: & mean horizontal wind $\bar{u} \geq 10 \mathrm{~m} / \mathrm{s}$ \\
Propagation: & wind shear $\Delta \alpha \leq \pm 45^{\circ}$ \\
Measurement: & GW potential energy density $\mathrm{GWPED}_{\mathrm{vol}}$ \\
& maximum vertical wavelength $\lambda_{\max }$ \\
\hline
\end{tabular}

dispersion relation, the vertical wave number can be written as $m=N /\left(\bar{u}-c_{p h}\right)$ (e.g. Fritts, 1984), where $N$ is the BruntVäisälä frequency, $\bar{u}$ is the mean horizontal wind speed in the direction of wave propagation and $c_{p h}$ is the horizontal phase velocity of the wave. For vertically ascending mountain waves the horizontal phase velocity is zero. Thus, the resulting maximum vertical wavelength, which can penetrate through an atmospheric level $z$ is given by

$\lambda_{\max }(z)=\overline{u(z)} P_{B}(z)$,

where $P_{B}=2 \pi / N$ is the Brunt-Väisälä period. As the lidar cannot determine the direction of wave propagation, we assume that in an overwhelmingly zonal wind the waves also propagate zonally. Using the ECMWF T106 data enables us to calculate this maximum vertical wavelength. The resulting range of wavelengths that can propagate is shown in Fig. 4.
From early January until the end of the major warming event the maximum vertical wavelength decreases to $5 \mathrm{~km}$ and even below in the middle stratosphere, which indicates a critical level below the $30-\mathrm{km}$ altitude. During this period there was a large transparency for gravity waves around the stratopause and higher up, allowing for values of $\lambda_{\max }>25 \mathrm{~km}$. A similar transparency occurred again during the minor warming at the beginning of February and lasted until 18 February. During the cold air event following the major warming, the stratosphere also became more transparent for gravity waves throughout nearly all of the stratosphere, allowing for values of $\lambda_{\max } \approx 25 \mathrm{~km}$. However, the critical levels in the troposphere prevented gravity wave penetration most of the time. Only during the second half of February did the troposphere allow wave propagation for long vertical wavelengths up to the tropopause, however, the low-altitude winds created critical levels in the lowermost atmospheric levels. The critical levels found in the ECMWF analyses clearly correspond with the wind observations of the ESRAD MST radar and the wave observations of the U. Bonn lidar. The parameters used to analyse and describe the dynamical state of the atmosphere are summarised in Table 1. 
(a)

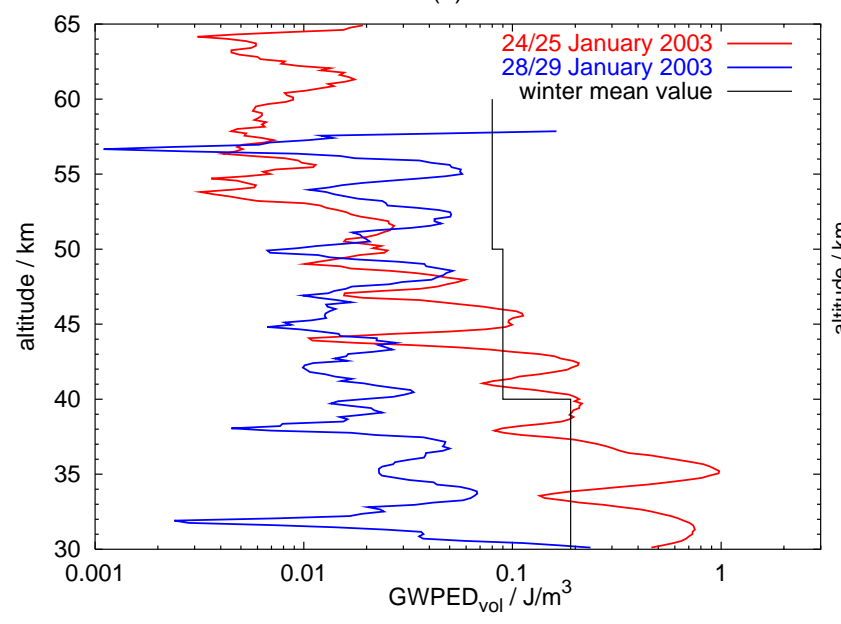

(b)

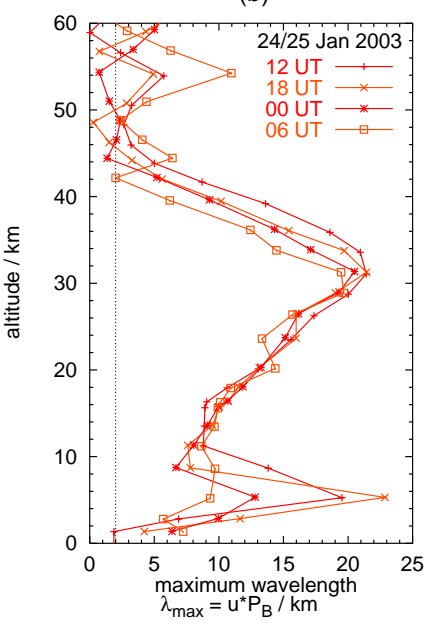

(c)

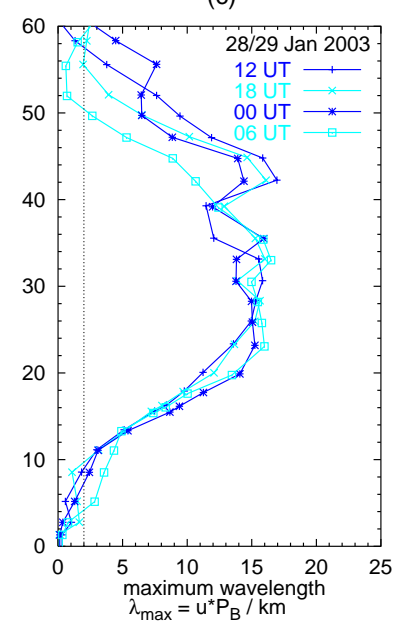

Fig. 5. The left plot (a) shows the gravity wave potential energy density profiles measured at Esrange for 24/25 January (red line) and $28 / 29$ January (blue line). Additionally shown is the winter mean value of the $G W P E D_{\text {vol }}$ for different altitude region (black line). The two subfigures (b) and (c) show the maximum vertical wavelength $\lambda_{\max }$ that can penetrate through the atmosphere for pure zonally penetrating stationary gravity waves on 24/25 January (b) and 28/29 January 2003 (c). Vertical lines at $\lambda_{\max }=2 \mathrm{~km}$ wavelength mark the minimum vertical wavelength observable by the lidar instruments.

\section{Propagation conditions during the rocket salvos}

The MaCWAVE winter campaign comprised essentially two salvos containing one sounding rocket each, and 13 and 6 meteorological rockets, respectively, launched on 24 and 28 January from Esrange (Goldberg et al., 2005). These salvos were carried out to investigate vertically ascending mountain waves. Below we focus on the analysis of wave propagation conditions on these two particular salvo days.

\subsection{Salvo: 24 January 2003}

The first salvo on 24 January took place during the afternoon and at night until the early morning of 25 January, which was in the middle of the period, showing the cold air reaching up to about $50 \mathrm{~km}$ altitude. The U. Bonn lidar observed during this salvo large $G W P E D_{\text {vol }}$ values up to about $45 \mathrm{~km}$ altitude (Fig. 3), indicating a critical level at about $45 \mathrm{~km}$ altitude.

Figure 5a presents the individual $G W P E D_{\text {vol }}$ profiles for both days, with salvos and mean winter values for different altitude regimes, obtained from lidar measurements from winter 1996/1997 to winter 2003/2004. Although the tropospheric winds prevented mountain waves from propagating through the troposphere most of the time, as seen in the radar data (see Fig. 3), the energy density on 24 January (red line) reaches values of about $0.5 \mathrm{~J} / \mathrm{m}^{3}$ at $30-40 \mathrm{~km}$ altitude and decreases below $0.01 \mathrm{~J} / \mathrm{m}^{3}$ above $50 \mathrm{~km}$, where it stays constant with altitude. Up to $45 \mathrm{~km}$ altitude this corresponds quite well with the mean winter values. The waves lose potential energy in the whole stratosphere, while propagating freely again in the mesosphere. However, the wave energy has already decreased by one order of magnitude.

Figure $5 \mathrm{~b}$ presents calculated maximum vertical wavelengths $\lambda_{\max }$, using the particular ECMWF data for $24 / 25$ January. The ECMWF T106 analyses are available every six hours, starting at 00:00 UT. For the figure the data for 12:00 UT, 18:00 UT, 00:00 UT and 06:00 UT for the following day were used.

On 24/25 January the troposphere and stratosphere were quite transparent for gravity waves, except the lowermost altitudes near the ground at 12:00 UT and for the region above $45 \mathrm{~km}$ altitude throughout the entire night. At these altitudes critical levels occurred, which reduced the maximum vertical wavelength to $2 \mathrm{~km}$ and less. The critical levels near the stratopause prohibited waves from penetrating into the mesosphere. From $30 \mathrm{~km}$ altitude onwards $\lambda_{\max }$ decreases continuously up to the critical level at $45 \mathrm{~km}$. This corresponds very well with the lidar observations. Obviously, gravity waves were able to propagate up into in the middle stratosphere, until reaching critical levels around the stratopause. In the mesosphere orographically induced gravity waves were essentially no longer observable.

\subsection{Salvo: 28 January 2003}

The second salvo took place on 28 January during the afternoon, which was right at the transition stage between the cold air tongue and the following warmer temperature period. On 28/29 January the weather conditions at Esrange were quite cloudy, thus the available lidar data set is of limited quality, resulting in a lower top altitude. The observed $G W P E D_{\text {vol }}$ (blue line, Fig. 5a) remained constant all the way up through 
the stratosphere, at a low level of about $0.02 \mathrm{~J} / \mathrm{m}^{3}$, which is about one order of magnitude below the winter mean value. This indicates that there were no gravity waves in this altitude range. The calculation of the maximum vertical wavelength $\lambda_{\max }$ (Fig. 5c) supports this observation. Throughout the troposphere critical levels arose. This was found in the ECMWF, as well as in the ESRAD data. Orographically induced gravity waves were not able to propagate upward at all. From 25 to $45 \mathrm{~km}$ altitude $\lambda_{\max }$ was quite stable at $\lambda_{\max } \approx 15 \mathrm{~km}$. Finally, the resulting maximum wavelength decreased in the lower mesosphere, again leading to a critical level at about $60 \mathrm{~km}$ altitude. Although the stratosphere was quite transparent, only a very small energy density was observed, with values less than $10 \%$ of the maximum values observed during the first salvo. However, these small values of about $0.02 \mathrm{~J} / \mathrm{m}^{3}$ reached up to an altitude of about $55 \mathrm{~km}$ (Fig. 5a). Thus, the critical level filtering close to the ground had been very effective in suppressing mountain waves. Interestingly, gravity waves from other sources were more or less absent during this night.

\section{Summary}

The Arctic winter atmosphere during January and February 2003 was dominated by one minor and one major stratospheric warming in the first half of January, which led to a wind reversal in the middle stratosphere and thus to critical level filtering of vertically ascending gravity waves. Following the major warming the stratosphere became transparent for gravity waves. The first rocket salvo of MaCWAVE was conducted during this transition stage. Due to a critical level filtering at about the $45-60 \mathrm{~km}$ altitude, stationary mountain waves were not able to penetrate into the mesosphere. During the second salvo, the stratosphere and lower mesosphere were transparent for gravity waves, however, the troposphere limited the vertical wavelength to low values, particular in the lowermost five kilometers of the atmosphere. These analyses from the ESRAD MST radar and the ECMWF T106 model confirm the lidar observations of the gravity wave potential energy density per volume, showing large values up to an altitude of about $45 \mathrm{~km}$ during the first salvo and only low $G W P E D_{\text {vol }}$ values in the measurement range up to $65 \mathrm{~km}$ altitude and low $G W P E D_{\text {vol }}$ values during the second salvo from $30 \mathrm{~km}$ upward. Following the second salvo, the transparency of the atmosphere stayed low. These findings correspond very well with the results of the meteorological rocket measurements, which showed gravity wave activity during the first salvo up to about $45-50 \mathrm{~km}$ altitude and during the second salvo only above $60 \mathrm{~km}$ altitude (Wang et al., 2005). The analysis of the ESRAD MST radar and ECMWF wind data imply that waves observed during the MaCWAVE salvos cannot be caused by orography. Also, during almost all of February, critical level filtering in the troposphere and lower stratosphere prevented orographically excited gravity waves from ascending to the mesosphere. Summarising, the period of January and February 2003 was not favourable for mountain wave penetration up to the mesosphere. The observation by the U. Bonn lidar at Esrange and the ALOMAR RMR lidar, as well as the ESRAD wind measurements and the meteorological background analysis by the ECMWF data, all agree in this respect and show this clearly.

Acknowledgements. We thank the staff of Esrange and the Andøya Rocket Range for their always quick and uncomplicated supported during the measurement campaigns. The lidar measurements at Esrange were funded by an Envisat Validation project grant from the DLR Erdbeobachtung FKZ 50 EE 0009. The lidar measurements at ALOMAR were supported by an "Access to the ALOMAR research infrastructure" project of the European Community. The work of the FU Berlin is part of the German HGF-project ENVISAT, funded by the Bundesministerium für Bildung und Forschung. The ECMWF data were made available by the Deutscher Wetterdienst and NILU. U. Blum is supported by the Marie-Curie Intra-European Fellowship programm of the European Community (MINERWA, No 010333).

Topical Editor U.-P. Hoppe thanks two referees for their help in evaluating this paper.

\section{References}

Blum, U. and Fricke, K. H.: The Bonn University lidar at the Esrange: technical description and capabilties for atmospheric research, Ann. Geophys., 23, 1645-1658, 2005.

Blum, U., Fricke, K. H., Baumgarten, G., and Schöch, A.: Simultaneous lidar observations of temperatures and waves in the polar middle atmosphere on the east and west side of the Scandinavian mountains: A case study on 19/20 January 2003, Atmos. Chem. Phys., 4, 809-816, 2004.

Blum, U., Fricke, K. H., Müller, K. P., Siebert, J., and Baumgarten, G.: Long-term lidar observations of polar stratospheric clouds at Esrange in northern Sweden, Tellus 57B, 412-422, 2005.

Briggs, B. H.: The analysis of spaced sensor records by correlation techniques, in: Handbook for MAP, edited by: Vincent, R. A., vol. 13, SCOSTEP Secr., Univ. of Ill., Urbana, 166-186, 1984.

Carslaw, K. S., Wirth, M., Tsias, A., Luo, B. P., Dörnbrack, A., Leutbecher, M., Volkert, H., Renger, W., Bacmeister, J. T., Reimer, E., and Peter, T.: Increased stratospheric ozone depletion due to mountain-induced atmospheric waves, Nature, 391, 675-678, doi:10.1038/35589, 1998.

Chilson, P. B., Kirkwood, S., and Nilsson, A.: The Esrange MST radar: A brief introduction and procedure for range validation using balloons, Radio Science, 34, 427-436, doi:10.1029/1998RS900023, 1999.

Dörnbrack, A. and Leutbecher, M.: Relevance of mountain waves for the formation of polar stratospheric clouds over Scandinavia: A 20 year climatology, J. Geophys. Res., 106, 1583-1593, doi:10.1029/2000JD900194, 2001.

Fritts, D. C.: Gravity wave saturation in the middle atmosphere: A review of theory and observations, Rev. Geophys., 22, 275-308, doi:10.1029/4R0411, 1984.

Fritts, D. C. and Alexander, M. J.: Gravity wave dynamics and effects in the middle atmosphere, Rev. Geophys., 41(1), 1003, doi:10.1029/2001RG000106, 2003. 
Goldberg, R. A.,Fritts, D. C., Schmidlin, F. J., Williams, B. P., Croskey, C. L., Mitchell, J. D., Friedrich, M., Russel III, J. M., Blum, U., and Fricke, K. H.: The MaCWAVE program to study gravity wave influences on the polar mesosphere, Ann. Geophys., 24, this issue, 2006.

Hauchecorne, A. and Chanin, M. L.: Density and temperature profiles obtained by lidar between 35 and $70 \mathrm{~km}$, Geophys. Res. Lett., 7, 565-568, 1980.

Kent, G. S. and Wright, R. W. H.: A review of laser measurements of atmospheric properties, J. Atmos. Terr. Phys., 32, 917-943, 1970.

Labitzke, K.: Temperature changes in the mesosphere and stratosphere connected with circulation changes in winter, J. Atmos. Sci., 29, 756-766, 1972.

Labitzke, K. and Naujokat, B.: The lower Arctic stratosphere in winter since 1952, SPARC Newsletter, 15, 11-14, 2000.

Matsuno, T.: A dynamical model of the stratospheric sudden warming, J. Atmos. Sci., 28, 1479-1494, 1971.

Meriwether, J. W. and Gerrad, A. J.: Mesospheric inversion layers and stratospheric temperature enhancements, Rev. Geophys., 42, doi:10.1029/2003RG000133, 2004.

Schöch, A., Baumgarten, G., Fritts, D. C., Hoffmann, P., Serafimovich, A., Wang, L., Dalin, P., Müllemann, A., and Schmidlin, F. J.: Gravity waves in the troposphere and stratosphere during the MaCWAVE/MIDAS summer rocket program, Geophys. Res. Lett., 31, doi:10.1029/2004GL019837, 2004.
Scorer, R. S.: Theory of mountain waves of large amplitude, Quart. J. R. Met. Soc., 75, 41-56, 1949.

Singleton, C. S., Randall, C. E., Chipperfield, M. P., Davies, S., Feng, W., Bevilacqua, R. M., Hoppel, K. W., Fromm, M. D., Manney, G. L., and Harvey, V. L.: 2002-2003 Arctic ozone loss deduced from POAM III satellite observations and the SLIMCAT chemical transport model, Atmos. Chem. Phys., 5, 597609, 2005.

Spang, R., Remedios, J. J., Kramer, L. J., Poole, L. R., Fromm, M. D., Müller, M., Baumgarten, G., and Konopka, P.: Polar stratospheric cloud observations by MIPAS on ENVISAT: detection method, validation and analysis of the northern hemisphere winter 2002/2003, Atmos. Chem. Phys., 5, 679-692, 2005.

Volkert, H. and Intes, D.: Orographically forced stratospheric waves over northern Scandinavia, Geophys. Res. Lett., 19, 1205-1208, 1992.

von Zahn, U., von Cossart, G., Fiedler, J., Fricke, K. H., Nelke, G., Baumgarten, G., Rees, D., Hauchecorne, A., and Adolfsen, K.: The ALOMAR Rayleigh/Mie/Raman lidar: Objectives, configuration, and performance, Ann. Geophys., 18, 815-833, 2000.

Wang, L., Fritts, D. C., Williams, B. P., Goldberg, R. A., Schmidlin, F. J., and Blum, U.: Gravity waves in the middle atmosphere during the MaCWAVE winter campaign: Evidence of mountain wave critical level encounters, Ann. Geophys., 24, this issue, 2006. 